\title{
Isolation of Streptococcus agalactiae in a female llama (Lama glama) in South Tyrol (Italy)
}

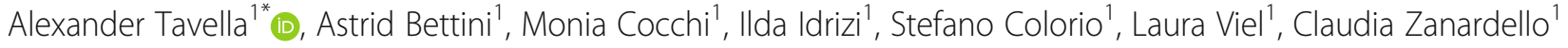 \\ and Patrik Zanolari ${ }^{2}$
}

\begin{abstract}
Background: Streptococcus agalactiae is pathogenic for both animals and humans. In dairy cattle it commonly causes mastitis, with great economic losses, and there is scientific evidence of mastitis, caseous lymphadenitis, contagious skin necrosis and purulent infections associated with S. agalactiae in camels (Camelus dromedarius) as well. In humans, it is a common component of the respiratory and gastrointestinal microflora, but it can also act as a pathogen, especially in elderly people and immunocompromised patients, as well as in pregrant women and newborns.

Case presentation: A 10-year old non-pregnant female llama (Lama glama) was conferred to the Institute for Animal Health Control, in Bolzano for necropsy after sudden death. The animal had not shown unusual behaviour and had a low to normal nutritional condition (body condition score 2/5). The breeder had reported a chronic suppurative subcutaneous infection in the intermandibular area, resistant to therapy (therapy unknown). After necropsy, several samples were processed for histological, bacteriological and parasitological examinations.

Conclusions: This report describes, to the best of our knowledge, the first isolation of S. agalactiae in llamas (Lama glama). The animal came from a herd that counts approximately 200 South American camelids (llamas, alpacas) along with several horses, chicken, rabbits, cats and dogs; this farm offers services, such as trekking and pet therapy activities.
\end{abstract}

Keywords: Streptococcus agalactiae, Lama glama, South American camelids, Lancefield group B Streptococcus

\section{Background}

Llamas and Alpacas have gained increasing interest in the last 10 years and are now frequently held as farm animals and for hobby purposes (trekking, pet therapy) in the alpine regions of Northern Italy. In the Autonomous Province of Bolzano - South Tyrol (Italy), the South American camelids (SACs) population has grown lately and currently counts 800 individuals (583 llamas and 217 alpacas - informations from the local Veterinary Service 2017-databank), representing an important niche product in local livestock breeding. In fact, SACs are often held in multispecies farming systems with sheep and horses, and could come into close contact with humans for trekking and pet therapy reasons.

\footnotetext{
* Correspondence: atavella@izsvenezie.it

${ }^{1}$ Istituto Zooprofilattico Sperimentale delle Venezie, Viale dell'Università 10, 35020 Legnaro, Italy

Full list of author information is available at the end of the article
}

Streptococcus agalactiae (S. agalactiae), a Lancefield Group B Streptococcus (GBS), is an important pathogen affecting both animals and humans [1]. In dairy cattle, it is a major cause of mastitis and an important source of economic loss [2]. GBS have also been found in many other animals, such as camels, dogs, cats, crocodiles, seals, fish and dolphins [3-5]. More in detail, S. agalactiae has been frequently observed in camels (Camelus dromedarius), as a causative agent of mastitis, caseous lymphadenitis, contagious skin necrosis and purulent infections [6-8]. Moreover, authors described that the camel strains are different from the bovine strains, and that they resemble much more the human strains [3]. To our knowledge, no $S$. agalactiae strains have been isolated from llamas (Lama glama).

S. agalactiae has also been observed in humans. It is a common component of the microflora of the respiratory and gastrointestinal tracts, approximately isolated in 
$30 \%$ of healthy humans. In the elderly and in immunocompromised patients, this bacterium can be associated with urinary tract and skin and soft-tissue infections, bacteremia, osteomyelitis, meningitis and endocarditis $[9,10]$. Moreover, in pregnant women, invasive maternal infection is associated with abortion, preterm delivery [11], sepsis and meningitis in newborns [12]. In humans, invasive infections caused by $S$. agalactiae are reported increasingly worldwide [13]. In the pathogenetic mechanism, the adherence to host epithelial cells is the first critical step of the infectious process, leading to the formation of microbial biofilms. These consist of microcolonies encased in extracellular polysaccharide material. Bacteria inside biofilms have increased resistance to antimicrobial agents and disinfectants [14]. Furthermore, the production of biofilms is correlated with both pathogenicity and virulence of the bacteria.

In this report, we describe the case of a 10-year-old non-pregnant female llama (Lama glama), conferred for necropsy to the Institute for Animal Health Control (Istituto Zooprofilattico Sperimentale delle Venezie, IZSVe) in Bolzano (Italy) after sudden death.

\section{Case presentation}

\section{Clinical history}

The animal had been kept all summer with other six llamas on an alpine pasture, but it originated from a larger llama breeding farm where no $S$. agalactiae-cases were ever recorded. The affected llama had not shown an unusual behavior. The breeder reported a chronic suppurative subcutaneous infection in the intermandibular area, that had persisted for several months. The nutritional condition of the individual was low to normal (body condition score 2/5) and was evaluated through adspection and palpation of the thorax, the abdomen and the back [15]. The animal was found dead by the breeder on the alpine pasture.

\section{Necropsy}

The physical exam revealed a $2-3 \mathrm{~cm}$ fistulating lump in the intermandibular area. After removing both hair and skin surfaces, a delimited suppurative infection site was observed in the subcutaneous tissue, in form of an abscess. Inspection of the anatomic area did not reveal a connection to the animal's oral cavity. A diffused subcutaneous oedema was noted in the intermandibular area, as well as in the neck and the caudal portion of the head. The retropharyngeal lymph nodes were enlarged and oedematous. After opening the lump, a yellowish creamy content was observed.

The exam of the abdominal cavity showed a severe sero-fibrinous ascites. The C3 intestinal compartment showed a catarrhal-haemorrhagic inflammation of the mucous membrane, while the proximal part of the bowel portion was hyperaemic; furthermore, a catarrhal duodenojejunitis was recognized. A severe nematode larvae infestation was identified in the intestinal content.

The liver had a light brown colour and a brittle consistency and showed a diffused necrosis.

In the thoracic cavity, a high-grade of sero-fibrinogenous pleural effusion was identified. The lung showed a pronounced oedema, as well as emphysematous areas; furthermore, an interstitial pneumonia was observed.

The pericardium and heart base were oedematous. No other pathological lesions were observed in any other organ.

Selected samples from liver and lung tissues were routinely processed for histopathological examination. Moreover, bacteriological examinations from the intermandibular abscess, the liver and the lungs were performed by routine laboratory tests, using blood agar (in-house protocol) at $37 \pm 1{ }^{\circ} \mathrm{C}$ in aerobiosis for $24 \mathrm{~h}$. The flotation procedure was performed, using a solution with specific gravity of 1.3 .

\section{Histology}

Samples of lung and liver parenchyma were first collected and fixed in $10 \%$ neutral buffered formalin, then processed, paraffin embedded, stained with Haematoxylin and Eosin (HE) and observed by standard light microscopy for histological examination. A diffuse mild to moderate neutrophilic and lymphocytic interstitial infiltration with alveolar emphysema was observed in the lung parenchyma (Fig. 1).

While examining the liver parenchyma, a multifocal necrosis of hepatocytes with foci of neutrophilic and lymphocytic infiltration and diffuse hydropic degeneration of hepatocytes were detected (Fig. 2).

\section{Bacterial examination}

After incubation, a pure culture of translucid grey colonies, with a complete $\beta$ hemolysis was submitted for identification. Gram staining revealed Gram positive cocci in linear chains, catalase negative, and esculin negative as well.

To confirm the presence of $ß$ hemolytic Streptococci, the CAMP test was performed, indicating a positive reaction, the serological assay (Streptococcal ${ }^{\mathrm{EN}}$ Grouping Kit, Oixoid, Wade road, Basingstoke, Hampshire, UK) was performed as well, showing group B antigens. Biochemical identification of isolates (api ${ }^{\oplus} 32$ Strep, bioMéerieux, Marcy-L'Etoile, France), revealed S. agalactiae (profile: 16122051110 ; \%ID $=81.2 ; T=0.77$ ), with an excellent level of genus identification.

S. agalactiae was isolated from the purulent material of the intermandibular abscess and from the pulmonary parenchyma.

Biofilm formation was evaluated using micro titer plates as described by Stepanovic and coworkers [14]. 


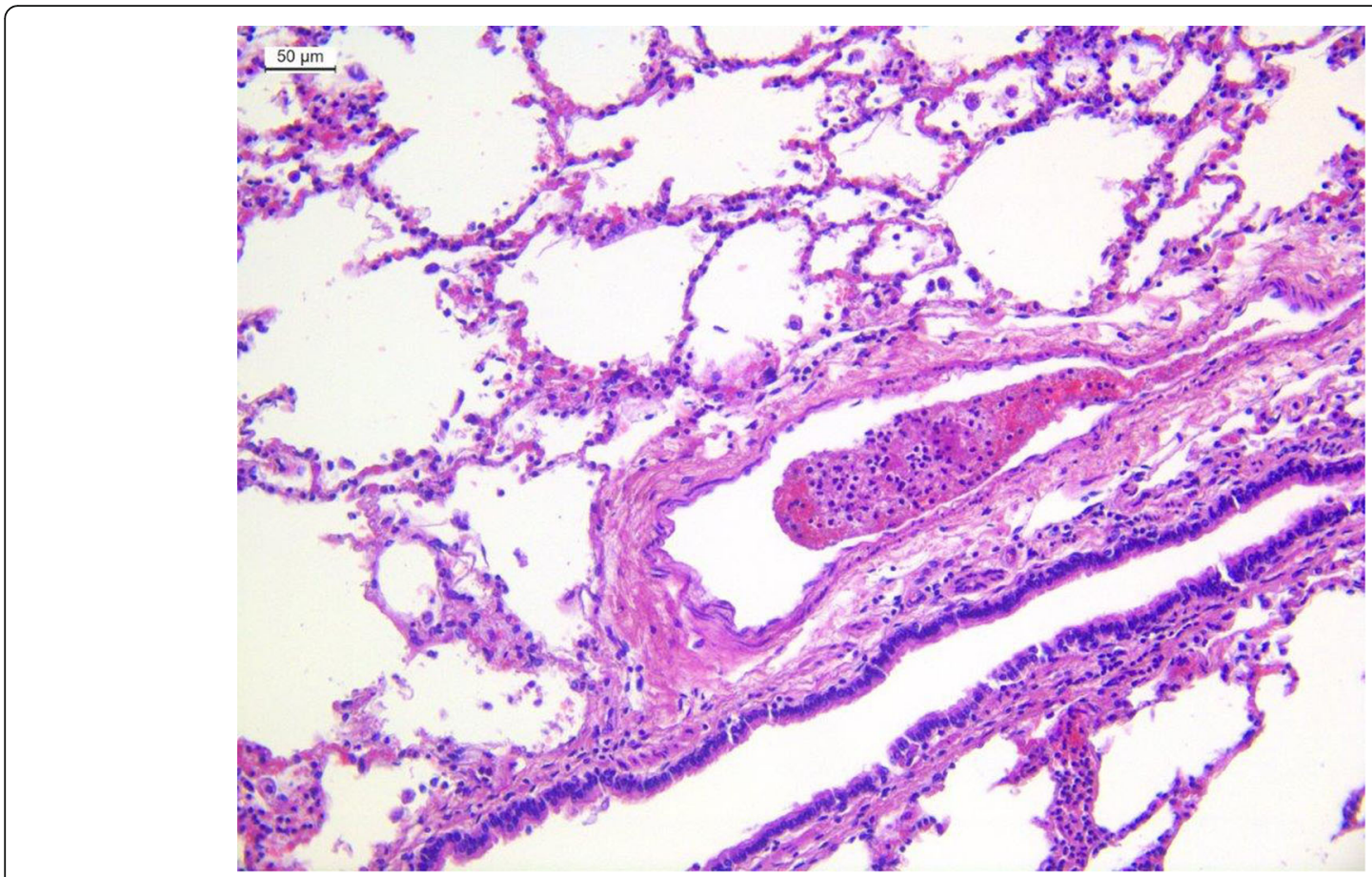

Fig. 1 Lung - Mild to moderate neutrophilic and lymphocytic interstitial infiltration with alveolar emphysema. Presence of a thrombus in the blood vessel. HE, 20X

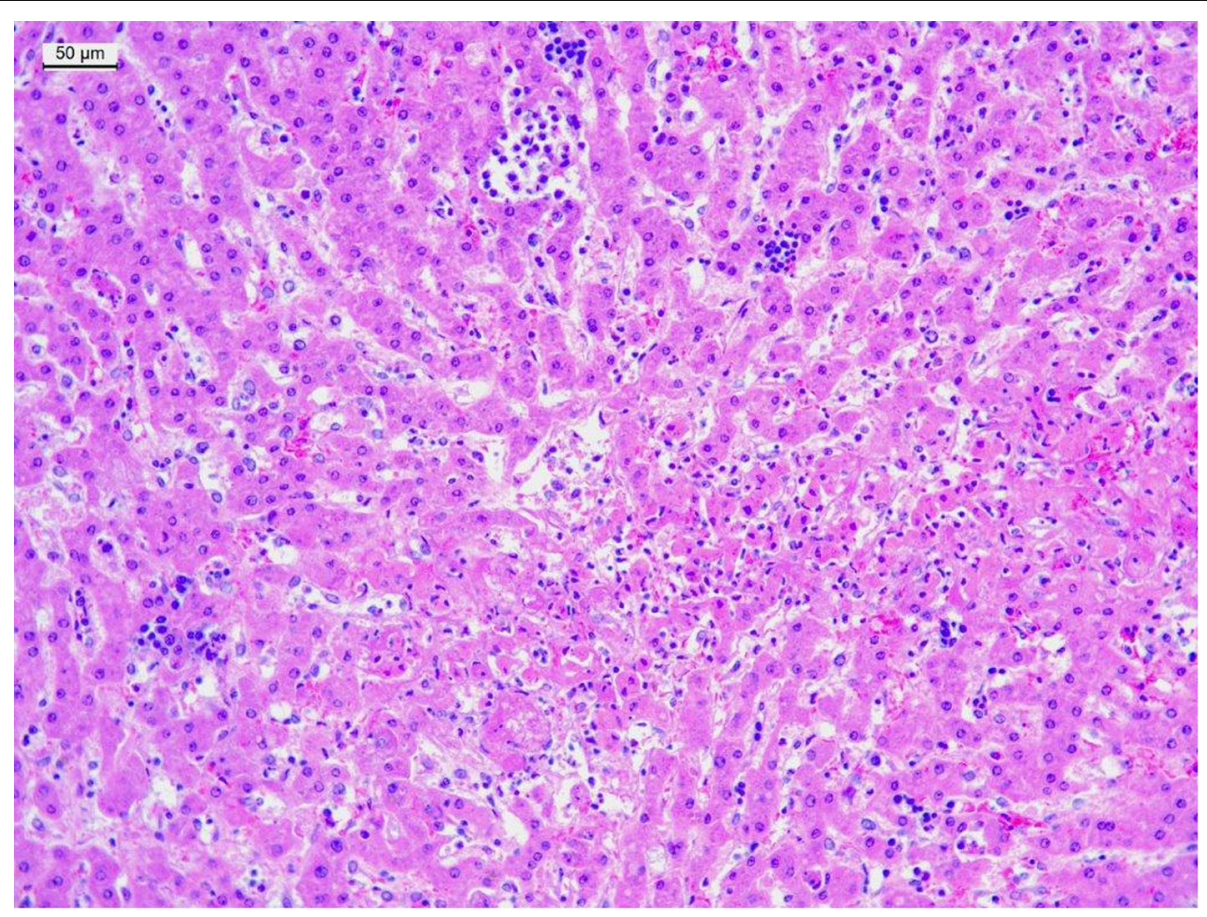

Fig. 2 Liver - Foci of necrosis of hepatocytes with neutrophilic infiltration. HE, 20X 
In order to confirm the identification of the isolated strains obtained from the abscess and from the lung, Matrix-Assisted Laser Desorption/Ionization Time-OfFlight Mass-Spectrometry (MALDI TOF MS) (Maldi Biotyper, Bruker Daltonics) was performed. This technique allows the identification of a bacterium by determining the molecular mass of fingerprint peptides (mainly ribosomal proteins), and comparing the mass fingerprint of the unknown strains to a database containing reference mass fingerprints. As specified by the manufacturer, a score value of $<1.7$ indicates that identification is not reliable, scores between 1.7 and 2.0 demonstrate that identification is reliable at the genus level, scores between 2.0 and 2.3 evidence that identification is reliable at the genus level and probable at the species level. Scores higher than 2.3 indicate highly probable species identification.

S. agalactiae strains were recognized with a score of 2.454 (abscess isolate), and a score of 2.465 (lung isolate), indicating a highly probable species identification.

The strains formed biofilms under in vitro conditions, and were identified as moderate biofilm producers.

\section{Determination of the minimum inhibitory concentration (MIC)}

Minimum Inhibitory Concentration (MIC) of the lung and abscess isolates was evaluated in accordance with the guidelines of the Clinical and Laboratory Standards Institute [16] for microwell dilution testing, using a commercial plate (Micronaut-S, Merlin, Kleinstrasse 14, Bornheim, Hersel, Germany). The antimicrobials tested were ampicillin, ceftiofur, enrofloxacin, florphenycol, spectinomycin, tetracycline, tilmicosin, trimethoprim/sulphamethoxazole. The MIC results are shown in Table 1.

\section{Parasitology}

Parasitology of the feces reported an elevated number of oval eggs with a thin single wall, measuring approximately $45 \times 30 \mu \mathrm{m}$, attributable to Strongyloides spp.. Several eggs had transformed to the larval stage. Furthermore, yellowbrownish eggs (approximately $70 \times 30 \mu \mathrm{m}$ ) showing a "lemon" shape with evident stoppers at the poles referred to Trichuris spp. were observed. The elevated number of eggs observed at the microscope and the evidence of the severe enteral parasitaemia allowed the indirect evaluation of the infestation intensity.

\section{Molecular characterization}

Both isolates were submitted for $16 \mathrm{~S}$ sequencing. The alignment using the NCBI GenBank BLAST function (Additional files 1 and 2) and the Clustal Omega application (Additional file 3) confirmed the identification of S. agalactiae.

\section{Discussion and conclusions}

S. agalactiae has already been isolated from skin lesions, periarticular abscesses and mastitic udder in camelids (Camelus dromedarius) [3, 6, 17]. Furthermore, it has been described as an opportunistic pathogen of the upper respiratory tract [18]. S. agalactiae has been isolated from caseus lymphadenitis, contagious skin necrosis and purulent infections in camels [3]; it has also been observed in wounds caused by Hyalomma spp. in dromedaries in Kenya [19]. So far, no S. agalactiae have been described in llamas, instead S. zooepidemicus, S. pyogenes, S. faecalis and S. uberis have been isolated from alpacas in Peru [20]. Therefore, to the best of our knowledge, this represents the first isolation of $S$. agalactiae from llamas (Lama glama).

In this report, the identification of $S$. agalactiae was performed in an abscess and in the lung parenchima in an animal presenting a parasitic infestation.

Parasitism in SACs has become a major health concern, as several parasites, in particular gastrointestinal nematodes, are believed to cause mild-to-severe clinical diseases and economic losses. Although death from parasitic gastroenteritis associated with gastrointestinal nematodes may occur, infections tend to be more insidious, often presenting nonspecific clinical signs (i.e. diarrhoea, anorexia and poor growth) or asymptomatic conditions [21]. Domesticated SACs, comprising llamas, often share pasture with other livestock species and are often farmed under more intensive grazing conditions as in their native countries, factors which may significantly increase the risk of nematode infections [22]. In the present case, an elevated number of eggs attributable to Strongyloides spp. and Trichuris spp. were observed: this has been identified in the large intestine of SACs in previous studies as well [21-23]. Infections with Trichuris spp. can lead to severe anemia [15], even though many clinical signs are often absent at the early stages of infection [24]. The abdominal cavity lesions observed can be ascribed to the intense infestation by gastrointesintal

Table 1 Inhibitory concentrations of the isolated S. agalactiae strain

\begin{tabular}{llllllll}
\hline Strain & $\begin{array}{l}\text { Ampicillin } \\
\mu \mathrm{g} / \mathrm{ml}\end{array}$ & $\begin{array}{l}\text { Ceftiofur } \\
\mu \mathrm{g} / \mathrm{ml}\end{array}$ & $\begin{array}{l}\text { Enrofloxacin } \\
\mu \mathrm{g} / \mathrm{ml}\end{array}$ & $\begin{array}{l}\text { Florfenicol } \\
\mu \mathrm{g} / \mathrm{ml}\end{array}$ & $\begin{array}{l}\text { Spectinomycin } \\
\mu \mathrm{g} / \mathrm{ml}\end{array}$ & $\begin{array}{l}\text { Tetracycline } \\
\mu \mathrm{g} / \mathrm{ml}\end{array}$ & $\begin{array}{l}\text { Tilmicosin } \\
\mu \mathrm{g} / \mathrm{ml}\end{array}$ \\
\hline Abscess & 0.125 & 0.125 & 0.5 & 1 & 128 & 0.25 & 4 \\
Lung & 0.125 & 0.125 & 0.5 & 1 & 128 & 0.25 & 4 \\
\hline
\end{tabular}


nematodes [23, 25]. Moreover, this could act as a predisposing factor for septicemic streptococcosis.

S. agalactiae is a component of the microflora of the respiratory, genital and gastrointestinal tracts in both humans and ruminants. In humans, GBS is also an important cause of morbidity and mortality in newborns, in the elderly and in immunocompromised adults [26]. Primary manifestations include bacteremia, skin and soft tissue infections, while other signs are referred to pneumonia, osteomyelitis and urinary tract infections [27, 28]. Furthermore, invasive infections are increasingly reported worldwide: Takahashi and coworkers [13] have highlighted significant differences in clinical aspects, including prognosis, between disease-entities caused by S. agalactiae and other Streptococci in human diseases. In veterinary medicine, $S$. agalactiae is the main cause of subclinical mastitis in cattle. To our knowledge, no report of septicemic conditions have been observed in SACs. In other species, the bacterial colonization and infection requires the capacity of the bacterium to adhere and to persist. The formation of biofilm-like communities could facilitate microbial survival and proliferation by enhancing resistance to host defenses and nutrient deprivation [29]. In our report, the isolates were indeed biofilm producers. The production of biofilm was correlated with pathogenicity and virulence of some bacteria [30]. In fact, microorganisms inside biofilms have increased resistance to antimicrobial agents and disinfectants, indicating the pathogenicity potential in the isolated strains. The analysis of virulence factors production was not performed in this report, though previous reports have highlighted the potential of virulence factors production by $S$. agalactiae in bovine mastitis [31]. Furthermore, biofilm formation appears to be a prerequisite for colonization of the bovine mammary gland. S. agalactiae isolates recovered from bovine subclinical mastitis produced different $\mathrm{pH}$-dependent biofilm levels, suggesting that biofilm production is modulated by environmental factors [28, 32]. No data are available for isolates from llamas.

Identification of the bacteria was performed by a commerical kit and by MALDI TOF MS. This last procedure is routinely used in many laboratories, and has shown to be a rapid and reliable technique for the identification of veterinary bacteria [33]. Furthermore, Lartigue and coworkers [34] have identified over $100 \mathrm{~S}$. agalactiae isolates, further charachterized by serotyping and multilocus sequence typing, with the use of MALDI TOF MS. Based on the previously described evaluation scores, a score higher than 2.3 allows the highly probable species identification. In this case report, $S$. agalactiae strains were identified with a score of 2.454 (abscess isolate), and a score of 2.465 (lung isolate).

The determination of MIC was performed in order to evaluate potential antimicrobial resistances. Since no
CLSI official breakpoints are available for llamas, and in order to provide a laboratory result, the MIC results (Table 1) were evaluated using the bovine clinical breakpoints, even though several authors have observed that llamas, but also other SACs, and bovines present different pharmacokinetics and pharmacodynamics [35, 36]. The evaluation, with bovine breakpoints, highlights sensitivity to all antimicrobials tested. While no official breakpoints are available for SACs, non official breakpoints have been proposed for ampicillin, ceftiofur and enrofloxacin [15]. Based on these data, the MIC results would suggest ampicillin and ceftiofur sensitivity by IV and IM administration, and an intermediate resistance to enrofloxacin by IV administration.

The breeding of SACs in the Autonomous Province of Bolzano - South Tyrol (Italy) has grown considerably in the last 10 years, conveying our Province a leading position in this field. These animals have gained great fame especially as hobby animals in zoos, private hotel gardens, as trekking animals and for pet therapy purposes, leading to a close contact between animals and humans, pointing out the possible risk of the transmission to humans. In fact, transmission of S. agalactiae from animals to humans has been briefly described in cattle [37, 38]; the authors describe a probable linkage between cattle exposure and detection of GBS in humans, stating that S. agalactiae can be transmitted between bovines and humans in a farm environment and that increased cattle exposure is associated with higher risk of infection. To this regard, no data are available for SACs, and molecular characterization of the isolates should be performed in order to establish the zoonotic potential of S. agalactiae.

\section{Additional files}

Additional file 1: BLAST allignment of the abscess isolate. (PDF $387 \mathrm{~kb}$ )

Additional file 2: BLAST allignment of the lung isolate. (PDF $397 \mathrm{~kb}$ )

Additional file 3: Clustal Omega allignment. (PDF 62 kb)

\section{Abbreviations}

CAMP test: Christie Atkins Munch Petersen test; CLSI: Clinical and Laboratory Standards Institute; GBS: Lancefield Group B Streptococcus; HE: Haematoxylin and Eosin; IM: Intramuscolar inoculation; IV: Intravenous inoculation; IZSVe: Istituto Zooprofilattico delle Venezie; m/z: Mass to charge ratio; MALDI TOF MS: Matrix- Assisted Laser Desorption/lonization Time-Of-Flight Mass Spectrometry; MIC: Minimum Inhibitory Concentration; S. agalactiae: Streptococcus agalactiae; SACs: South American camelids

\section{Acknowledgements \\ $\mathrm{N} / \mathrm{A}$}

\section{Funding}

N/A

Availability of data and materials

All data generated or analysed during this study are included and shared in this article. 


\section{Authors' contributions}

AT performed necropsy and developed the manuscript, AB co-authored the manuscript, MC performed bacteriological examinations, II performed necropsy and parasitology, SC co-authored the manuscript, LV executed Maldi-Tof and MIC examinations, CZ performed histopathological examinations, PZ provided scientific and technical support. All authors read and approved the final manuscript.

\section{Ethics approval and consent to participate}

No ethical approval was required.

\section{Consent for publication}

No personal data was included in the manuscript; no consent for publication was applicable.

\section{Competing interests}

The authors declare that they have no competing interests.

\section{Publisher's Note}

Springer Nature remains neutral with regard to jurisdictional claims in published maps and institutional affiliations.

\section{Author details \\ 'Istituto Zooprofilattico Sperimentale delle Venezie, Viale dell'Università 10, 35020 Legnaro, Italy. ${ }^{2}$ Clinic for Ruminants, Vetsuisse-Faculty, University of} Bern, Bremgartenstrasse 109A, 3012 Bern, Switzerland.

\section{Received: 16 February 2018 Accepted: 30 October 2018} Published online: 13 November 2018

\section{References}

1. Fischer A, Liljander A, Kaspar H, Muriuki C, Fuxelius HH, Bongcam-Rudloff E, de Villiers EP, Huber CA, Frey J, Daubenberg C, Bishop R, Younan M, Jores J. Camel Streptococcus agalactiae populations are associated with specific disease complexes and acquired the tetracycline resistance gene tet $M$ via a Tn916-like element. Vet Res. 2013;44:86.

2. Lyhs U, Kulkas L, Katholm J, Waller KP, Saha K, Tomusk RJ, Zadoks RN. Streptococcus agalactiae serotype IV in humans and cattle. Northern Europe Emerg Infect Dis. 2016;22:2097-103.

3. Younan $\mathrm{M}$, Bornstein $\mathrm{S}$. Lancefield group $B$ and $\mathrm{C}$ streptococci in east African camels (Camelus dromedarius). Vet Rec. 2007a;160:330-5.

4. Delannoy CMK, Crumlish M, Fontaine MC, Pollock J, Foster G, Dagleish MO, Turnbull JF, Zadocks RN. Human Streptococcus agalactiae strains in acquatic mammal and fish. BMC Microbiol. 2013;13:41.

5. Ma Y, Hao L, Ke H, Liang Z, Ma J, Liu Z, Li Y. LuxS/Al-2 in Streptococcus agalactiae reveals a key role in acid tolerance and virulence. Res Vet Sci. 2017;115:501-7.

6. Younan M, Müller W, Bornstein S. Streptococcus agalactiae infections in camels (Camelus dromedarius) in Kenya. Rev Élev Méd Vét Pays Trop. 2001a; 53:169-71.

7. Younan M, Ali Z, Mueller W, Bornstein S. Application of the California mastitis test in intramammary Streptococcus agalactiae and Staphylococcus aureus infections in camels (Camelus dromedarius) in Kenja. Prev Vet Med. 2001b;51:307-16.

8. Zubair S, de Villiers EP, Younan M, Andersson G, Tettelin H, Riley DR, Jores J, Bongcam-Rudloff E, Bishop RP. Genome sequences of two pathogenic Streptococcus agalactiae isolated from the one-humped camel Camelus dromedaries. Gen Ann. 2013;1:4.

9. Edwards MS, Baker CJ. Group B streptococcal infections in elderly adults. Clin Inf Dis. 2005;41:839-47.

10. Farley MM. Group B streptococcal disease in non pregnant adults. Clin Inf Dis. 2001;33:556-61.

11. Tevdorashvili G, Tevdorashvili D, Andqhuladze M, Tevdoarshvili M. Prevention and treatment strategy in pregnant women with group $B$ streptococcal infection. Georg Med News. 2015;241:15-23.

12. Manning SD, Springman AC, Million AD, Milton NR, McNamara SE, Somsel PA, Bartlett P, Davies HD. Association of Group B Streptococcus Colonization and Bovine Exposure: a prospective cross-sectional cohort study. PLoS One. 2010;5:1. https://doi.org/10.1371/journal.pone.0008795.
13. Takahashi T, Ubukata K, Watanabe H. Invasive infection caused by Streptococcus dysgalactiae subsp. equisimilis: characteristics of strains and clinical features. J Infect Chemot. 2011;17(1):1-10.

14. Stepanović S, Cirković I, Ranin L, Svabić-Vlahović M. Biofilm formation by Salmonella spp. and Lysteria monocytogenes on plastic surface. Let Appl Microbiol. 2004;38:428-32.

15. Cebra C, Anderson DE, Tibary A, Van Saun RJ, Johnson LW. Nutritional Assessment. In: Lama and alpaca care: medicine, surgery, reproduction, nutrition and herd health. 1st ed. Amsterdam: Elvesier; 2014. p. 112-3.

16. Clinical and Laboratory Standards Institute (CLSI). Performance Standards for Antimicrobial Disk and Dilution Susceptibility Tests for Bacteria Isolated from Animals; Approved Standard. 4th ed. Wayne: VET01-A4; 2013.

17. Tibary A, Fite C, Anouassi A, Sghiri A. Infectious cases of reproductive loss in camelids. Theriogen. 2006;66:633-47.

18. Younan M, Bornstein S, Glück IV. Peri-arthricular abscesses in camel calves in North Kenya. J Cam Prac Res. 2007b;14:161-4.

19. Wernery U, Kaaden OR. Infestations with Ectoparasites. In: Infectious diseases in camelids. 2nd ed. Vienna: Blackwell Science Berlin; 2002. p. 328-9.

20. Fowler ME. Infectious diseases. In: Medicine and surgery of south American camelids. 3rd ed. Ames: Blackwell Publishing; 2010. p. 148-94.

21. Ballweber LR. Ecto- and endoparasites of New World camelids. Vet Clin North Am Food Anim Pract. 2009;25(2):295-310. https://doi.org/10.1016/j. cvfa.2009.02.003.

22. Jabbar A, Campbell AJD, Charles JA, Gasser RB. First report of anthelmintic resistance in Haemoncus contortus in alpacas in Australia. Parasit Vectors. 2013;6:243. https://doi.org/10.1186/1756-3305-6-243.

23. Rohbeck S. Parasite infections of the digestive and respiratory systemms of South American camelids: Investigations on their epidemiology and control measures in a herd in sourthern Hessen, Germany and the biology of Eimeria macusaniensis. Giessen: Thesis doctor of veterinary medicine, Justus Liebig University; 2006.

24. Franz S, Wittek T, Joachim A, Hinney B, Dadak AM. Llamas and alpacas in Europe: Endoparasites of the digestive tract and their pharmacotherapeutic control. Vet J. 2015;204(3):255-62. https://doi.org/10.1016/j.tvj.2015.04.019.

25. Sprenger LK, Yoshitani UY, Buzatti A, Molento MB. Occurrence of gastrointestinal parasites in wild animals in state of Paranà, Brazil. An Acad Bras Cienc. 2018;90(1):231-8. https://doi.org/10.1590/00013765201720150030

26. Schuchat A. Epidemiology of group B streptococcal disease in the United States: shifting paradigms. Clin Microbiol Rev. 1998;11(3):497-513.

27. Krzysciak W, Pluskwa K, Jurczak A, Koscielniak D. The pathogenicity of the Streptococcus genus. Eur J Clin Microbiol Infect Dis. 2013:32:1361-76.

28. Rosini R, Immaculada M. Biofilm formation by Streptococcus agalactiae: influence of environmental conditions and implicated virulence factors. Front Cell Infect Microbiol. 2015;5:1-4. https://doi.org/10.3389/fcimb.2015.00006.

29. Ebrahimi A, Moatamedi A, Lotfalian S, Mirshokraei P. Biofilm formation, hemolysin production and antimicrobial susceptibilities of Streptococcus agalactiae isolated from the mastitis milk of dairy cows in Shahrekord district. Iran Vet Res Forum. 2013;4:269-72.

30. Costerton JW, Lewandowski Z, Caldwell DE, Korber DR, Lappin-Scott HM. Microbial biofilms. Annu Rev Microbiol. 1995:49:711-45.

31. Kaczorek E, Malaczewska J, Wòjcik R, Siwicki AK. Biofilm production and other virulence factors in Streptococcus spp. isolated from clinical cases of bovine mastitis in Poland. BMC Vet Res. 2017;13:398. https://doi.org/10.1186/ s12917-017-1322-y.

32. Miranda PSD, Lannes-Costa PS, Pimentel BAS, Silva LG, Ferreira-Carvalho BT, Menezes GC, Mattos-Guaraldi AL, Hirata RJ, Mota RA, Nagao PE. Biofilm formation on different $\mathrm{pH}$ conditions by Streptococcus agalactiae isolated from bovine mastitic milk. Lett Appl Microbiol. 2018. https://doi.org/10. 1111/lam.13015

33. Randall LP, Lemma F, Koylass M, Rogers J, Ayling RD, Worth D, Klita M, Steventon A, Line K, Wragg P, Muchowski J, Kostrzewa M, Whatmore AM. Evaluation of MALDI-ToF as a method for the identification of bacteria in the veterinary diagnostic laboratory. Res Vet Sci. 2015;101:42-9. https://doi. org/10.1016/j.rvsc.2015.05.018.

34. Lartigue MF, Héry-Arnaud G, Haguenoer E, Domelier AS, Schmit PO, van der Mee-Marquet N, Lanotte P, Mereghetti L, Kostrzewa M, Quentin R. Identification of Streptococcus agalactiae isolates from varioius phylogenetic lineages by matrix-assisted laser desorption ionization-time of fligt mass spectrometry. J Clin Microbiol. 2009;47(7):2284-7. https://doi.org/ 10.1128/JCM.00175-09. 
35. Rubio-Langre S, De Lucas JJ, Litterio NJ, Aguilar S, Boggio JC, San Andrès MI. Pharmacokinetic behavior of marbofloxacin after intravenuous, subcutaneous and intramuscular administration in llamas (Lama glama). Small Ruminant Res. 2012;106(1):64-9.

36. Kreil V, Ambros L, Prados AP, Tarragona L, Monfrinotti A, Bramuglia G, Rebuelto M. Pharmacokinetics of immediate and sustained release cephalexin administered by different routes to llamas (Lama glama). Adv Pharmacol Sci. 2016;2016:1-6. https://doi.org/10.1155/2016/4621039.

37. Keefe GP. Streptococcus agalactiae mastitis: a review. Can Vet J. 1997;38: 429-37.

38. Carvalho-Castro GA, Silva JR, Paiva LV, Custòdio DAC, Moreira RO, Mian GF, Prado IA, Chalfun-Junior A, Costa GM. Molecular epidemiology of Streptococcus agalactiae isolated from mastitis in Brazilian dairy herds. Braz Microbiol. 2017;48:551-9. https://doi.org/10.1016/j.bmj.2017.02.004.

Ready to submit your research? Choose BMC and benefit from:

- fast, convenient online submission

- thorough peer review by experienced researchers in your field

- rapid publication on acceptance

- support for research data, including large and complex data types

- gold Open Access which fosters wider collaboration and increased citations

- maximum visibility for your research: over $100 \mathrm{M}$ website views per year

At BMC, research is always in progress.

Learn more biomedcentral.com/submissions 